\title{
Progresso genético em caracteres agronômicos no melhoramento do feijoeiro
}

\author{
Genetic gain in agronomic traits in common bean breeding
}

\author{
Nerinéia Dalfollo Ribeiro ${ }^{1}$ Sandro Borba Possebon ${ }^{2}$ \\ Lindolfo Storck ${ }^{3}$
}

\section{RESUMO}

Com o objetivo de estimar o progresso genético para rendimento de grãos e outras características de importância para o melhoramento do feijoeiro, foram conduzidos quatro ensaios de valor de cultivo e uso (EVCU), na região da depressão central do Rio Grande do Sul, durante os anos de 1998 a 2002. O progresso genético foi estimado para cada ano, considerando-se os genótipos comuns aos dois anos sucessivos. Os resultados obtidos mostraram que o ganho genético médio anual para rendimento de grãos foi de 0,88\%, o que corresponde a $18,07 \mathrm{~kg} \mathrm{ha}^{-1}$ ano $^{-1}$. Perdas genéticas para coloração do tegumento dos grãos, altura de inserção do primeiro e do último legume foram constatadas. Ganhos genéticos de pequena magnitude foram observados para ciclo e massa de 100 grãos.

Palavras-chave: Phaseolus vulgaris, ganho genético, genótipos.

\section{ABSTRACT}

The objective of this work was to estimate genetic gain for grain yield and other important breeding traits of common bean. The experiments were conducted in the central region of Rio Grande do Sul, Brazil, in four grow seasons. The genetic gain was estimate for each year, considering common genotype in two sequencial years. The results showed that annual mean genetic gain for grain yield was $0.88 \%$, which corresponded to $18.07 \mathrm{~kg} \mathrm{ha}^{-1}$ year-1. Genetic loss was verified in colour of grain tegument, height of first and final pod insertion. Small genetic gain was observed for cycle and weight of 100 grains.

Key words: Phaseolus vulgaris, genetic gain, genotypes.

\section{INTRODUÇÃO}

As pesquisas de melhoramento genético do feijoeiro iniciaram na década de trinta no Instituto Agronômico de Campinas (IAC), porém receberam maior ênfase a partir da década de setenta, com a criação da EMBRAPA e de várias empresas estaduais de pesquisa (RAMALHO, 2001). Com o desenvolvimento de cultivares por essas instituições, tornou-se possível produzir feijão em todos os meses do ano e com ganhos em produtividade (POMPEU, 1993; ABREU et al., 1994). Estudos realizados nos últimos anos indicam grande progresso na produtividade do feijoeiro no país, o que pode ser atribuído ao melhoramento genético (RAMALHO, 2001).

No Brasil, foram semeados 4,34 milhões de hectares com feijão sendo que, aproximadamente, 77\% dessa área foi ocupada com Phaseolus vulgaris L., o que corresponde a 3,34 milhões de hectares (RAMALHO, 2001). Considerando-se o progresso genético médio estimado por ABREU et al. (1994), ou seja, $17,46 \mathrm{~kg} \mathrm{ha}^{-1}$ ano $^{-1}$, tem-se o crescimento anual de 58,3 milhões de $\mathrm{kg}$ de grãos por ano. $\mathrm{O}$ preço médio recebido pelos agricultores, no período de 1990 a 199,7 foi de $0,79 \mathrm{~kg}^{-1}$ (AGROANALYSIS, 1998). Com isso tem-se um incremento na renda anual dos agricultores superior a 43 milhões de reais

${ }^{1}$ Engenheiro Agrônomo, Doutor, Professor Adjunto, Departamento de Fitotecnia, Universidade Federal de Santa Maria (UFSM) 97105-900, Santa Maria-RS. E-mail: nerineia@ccr.ufsm.br.

${ }^{2}$ Aluno do Curso de Agronomia, UFSM. Bolsista do PET/Sesu.

${ }^{3}$ Engenheiro Agrônomo, Doutor, Professor Titular, Departamento de Fitotecnia, UFSM. Bolsista do CNPq. 
(VENCOVSKY \& RAMALHO, 2000) se estes adotarem, anualmente, as novas cultivares. Progressos obtidos em programas de melhoramento genético devem ser avaliados, freqüentemente, com o objetivo de orientar futuras ações da pesquisa. Essa avaliação pode ser realizada por diferentes procedimentos. O primeiro a ser destacado é baseado no número e na área ocupada pelas cultivares 'recomendadas'. Esse processo, no entanto, é falho, pois a eficiência avaliada não é apenas do programa de melhoramento, mas também da difusão das novas cultivares, a qual, na maioria das vezes, independe do melhorista (ABREU et al., 1994).

O segundo procedimento utiliza a comparação entre as cultivares recentemente 'recomendadas' e as primitivas. Com o emprego desse, POMPEU (1993) observou, em um período inferior a 30 anos, incremento de $40 \%$ na produtividade do feijoeiro no estado de São Paulo, o que fornece um ganho anual superior a $1,3 \%$. No entanto, a utilização dessa metodologia, necessita a condução de experimentos específicos para essa finalidade e o armazenamento do germoplasma primitivo, sem alterações genéticas.

Por fim, podem-se utilizar resultados de experimentos para registro de cultivares, conduzidos por vários anos em uma determinada região. Considerando-se que nesses ensaios há a substituição anual de linhagens, avalia-se a eficiência em função da superioridade genética dos genótipos que participam em um determinado ano, em relação ao ano anterior (VENCOVSKY et al., 1986). Sendo assim, ganhos anuais de 1,90\% em Minas Gerais (ABREU et al., 1994), de 1,21\% em Santa Catarina (ELIAS et al., 1999), de 0,74\% no Rio Grande do Sul (ANTUNES et al., 2000), de 1,99\% para o grupo preto e de $1,02 \%$ para o grupo de cores no Paraná (FONSECA JÚNIOR et al., 1996a; FONSECA JÚNIOR et al., 1996b) foram obtidos na produtividade do feijoeiro.

No entanto, todas as estimativas encontradas do progresso genético com a cultura do feijoeiro referem-se apenas a ganhos em produtividade de grãos. Em vista disso, o objetivo deste trabalho foi o de quantificar o progresso genético em ciclo, coloração do tegumento dos grãos, altura de inserção de primeiro legume, altura de inserção de último legume, massa de 100 grãos e rendimento de grãos em ensaios de valor de cultivo e uso (EVCU), conduzidos na região da depressão central do Rio Grande do Sul, com a finalidade de orientar as novas propostas para pesquisa em melhoramento genético do feijoeiro.

\section{MATERIAL E MÉTODOS}

Os experimentos foram conduzidos em área do Departamento de Fitotecnia da Universidade Federal de Santa Maria, em solo da Unidade de Mapeamento Santa Maria (Brunizem Hidromórfico). O local de condução dos ensaios apresenta as seguintes coordenadas geográficas: $29^{\circ} 41^{\prime} 25^{\prime}$ ' de latitude sul, $53^{\circ} 48^{\prime} 04$ " de longitude oeste e altitude de $95 \mathrm{~m}$. A semeadura foi realizada em diferentes datas: 14/10/ 1998, 22/09/1999, 07/11/2000 e 06/11/2001 e a densidade foi ajustada de acordo com o hábito de crescimento de cada genótipo (CEPEF, 2000).

$\mathrm{O}$ delineamento experimental utilizado foi o de blocos ao acaso, com três repetições. As parcelas foram compostas de quatro fileiras, com $4 \mathrm{~m}$ de comprimento, espaçadas de $0,50 \mathrm{~m}$. A área útil foi formada pelas duas fileiras centrais, desprezando $0,50 \mathrm{~m}$ das extremidades, compreendendo $3 \mathrm{~m}^{2}$. Os tratamentos consistiram de genótipos de feijão do ensaio de valor de cultivo e uso (EVCU) do estado do Rio Grande do Sul, em número variável a cada ano, sendo utilizada como padrão (testemunha) a cultivar TPS Nobre (Tabela 1).

O preparo do solo foi realizado de forma convencional e as adubações foram baseadas na análise química do solo, seguindo as Recomendações de Adubação e Calagem para os Estados do Rio Grande do Sul e Santa Catarina (ROLAS, 1995). O controle de insetos foi efetuado com aplicação de Metamidofós (Metamidofós Fersol, na dose de $750 \mathrm{ml} \mathrm{ha}^{-1}$ ) e, para a eliminação de plantas invasoras, usou-se o herbicida Fluazifop-p-butyl (Fusilade, na dose de $850 \mathrm{ml} \mathrm{ha}^{-1}$ ) e o arranquio manual de plantas remanescentes. Esses tratos culturais e a irrigação foram realizados sempre que necessário, de forma a não prejudicar o desenvolvimento normal da cultura. Não se fez controle de doenças, a fim de se verificar a ocorrência de patógenos nos genótipos.

O rendimento de grãos (REND) foi determinado com as sementes a $13 \%$ de umidade $\left(\mathrm{kg} \mathrm{ha}^{-1}\right)$ e a cor do tegumento dos grãos (COR) foi medida através do sistema $\mathrm{L}-\mathrm{a}-\mathrm{b}$, determinado com o colorímetro, marca Minolta, modelo CR - 310, logo após a colheita dos grãos. O eixo vertical ' $L$ ' avalia a claridade da cor da amostra, variando do preto ao branco; o eixo 'a' da cor verde ao vermelho; e o ' $b$ ', da cor azul ao amarelo. Para o feijoeiro, importa a claridade dos grãos, razão pela qual foram apresentados apenas valores de 'L'. Além dessas variáveis, considerou-se também a altura de inserção do primeiro legume, altura de inserção do último legume e a massa de 100 grãos, medidos em cinco plantas coletadas ao acaso na 
Tabela 1 - Genótipos avaliados de feijoeiro na região da depressão central do Rio Grande do Sul, nos quatro anos agrícolas. Santa Maria-RS, UFSM, 2002.

\begin{tabular}{|c|c|c|c|c|c|}
\hline Genótipo & Grupo & $\mathrm{HC}$ & Genótipo & Grupo & $\mathrm{HC}$ \\
\hline \multicolumn{3}{|c|}{1998 / 99} & \multicolumn{3}{|c|}{$1999 / 00$} \\
\hline FPGCF 058 & preto & II & TB 95-02 & preto & II \\
\hline FE 821732 & preto & II & TВ 95-01 & preto & II \\
\hline FPGCF 101 & preto & II & MT 95202057 & preto & II \\
\hline M 91-012 & carioca & III & M8985-2 & preto & III \\
\hline Diamante Negro & preto & II & SM 89153 & preto & II \\
\hline ТВ 94-20 & preto & II & Pérola & carioca & III \\
\hline TPS Nobre & preto & II & Carioca & carioca & III \\
\hline Macotaço & preto & II/III & Macotaço & preto & II/III \\
\hline ТВ 94-06 & preto & II & TPS Nobre & preto & II \\
\hline Carioca & carioca & III & ТВ $97-13$ & preto & II \\
\hline Pérola & carioca & III & LM 92204133 & preto & II \\
\hline SM 89153 & preto & II & SM 97-08 & preto & III \\
\hline M 8985-2 & preto & III & TB 97-07 & preto & II \\
\hline M 89148-2 & preto & II & LM 93204217 & preto & II \\
\hline TB 95-01 & preto & II & ТВ 96-08 & preto & II \\
\hline ТВ 95-03 & preto & II & M 8990 & preto & II \\
\hline ТВ 95-02 & preto & II & SM 97-04 & preto & II \\
\hline ТВ 94-09 & preto & II & TB 94-01 & preto & II \\
\hline TB 94-08 & preto & II & SM 8915 & preto & II \\
\hline MT 95202057 & preto & II & LM 95102835 & carioca & III \\
\hline \multicolumn{3}{|c|}{$2000 / 01$} & \multicolumn{3}{|c|}{$2001 / 02$} \\
\hline TPS Nobre & preto & II & TPS Nobre & preto & II \\
\hline Diamante Negro & preto & II & Diamante Negro & preto & II \\
\hline CNFP-8097 & preto & II & CNFP-8097 & preto & II \\
\hline CI-9867 & preto & II & CI-9867 & preto & II \\
\hline CI-9637 & preto & II & CI-9637 & preto & II \\
\hline CI-9690 & preto & II & CI-9690 & preto & II \\
\hline CI-9844 & preto & III & CI-9844 & preto & III \\
\hline CNFP-8100 & preto & III & CNFP-8100 & preto & III \\
\hline CNFP-8104 & preto & III & CNFP-8104 & preto & III \\
\hline $\begin{array}{l}\text { CNFP-7560 } \\
\text { (Valente) }\end{array}$ & preto & III & $\begin{array}{l}\text { CNFP-7560 } \\
\text { (Valente) }\end{array}$ & preto & III \\
\hline CNFP-8078 & preto & III & CNFP-8078 & preto & III \\
\hline ТВ 96-11 & preto & III & TВ 96-11 & preto & III \\
\hline ТВ 96-09 & preto & II & ТВ 96-13 & preto & II \\
\hline ТВ 96-13 & preto & II & TВ $97-13$ & preto & II \\
\hline CI-9849 & preto & III & TB 94-01 & preto & II \\
\hline CNFP-8087 & preto & II & LP 98-13 & preto & II \\
\hline LP 98-13 & preto & II & LM 92204133 & preto & II \\
\hline ТВ $97-13$ & preto & II & SM 9809 & preto & II \\
\hline ТВ 94-01 & preto & II & & & \\
\hline LM 92204133 & preto & II & & & \\
\hline MT 95202057 & preto & II & & & \\
\hline M 8990 & preto & III & & & \\
\hline SM 9707 & preto & II & & & \\
\hline SM 9809 & preto & II & & & \\
\hline
\end{tabular}

* HC: hábito de crescimento: II - indeterminado com guias curtas e IIIindeterminado com guias longas. parcela útil. O ciclo cultural foi baseado no número de dias da emergência até a colheita das plantas. Para avaliar o ganho genético, foram identificados os genótipos comuns a dois anos sucessivos e estimada a média $\left(\tilde{Y}_{\mathrm{ci}}\right)$ para cada ano, utilizando-se o método apresentado por Vencovsky et al. (1986). Os dados foram coletados em $n$ anos, e o ganho genético (Ga) por ano, em relação ao ano anterior, foi obtido pelo contraste: $G_{a k}=\tilde{Y}_{i}-\tilde{Y}_{j}-\left(\tilde{Y}_{i}-\tilde{Y}_{c j}\right)$. Para $i>j$, onde: $\mathrm{G}_{\mathrm{ak}}=$ ganho genético no par de anos i e j; $\tilde{\mathrm{Y}}_{\mathrm{i}}$ $=$ média geral das cultivares no ano $\mathrm{i} ; \mathrm{Y}_{\mathrm{j}}=$ média geral das cultivares no ano $\mathrm{j}$, sendo $\mathrm{j}=\mathrm{i}+1 ; \tilde{Y}_{\mathrm{ci}}$ $\tilde{Y}_{\mathrm{cj}}=$ média geral das cultivares comuns aos anos i e j, respectivamente.

O ganho genético total foi estimado por:<smiles>[GeH2]=[GeH2]</smiles>

O ganho genético médio anual foi estimado:<smiles>[GeH2]=[GeH2]</smiles>

\section{RESULTADOS E DISCUSSÃO}

Nos ensaios de valor de cultivo e uso (EVCU), conduzidos na região da depressão central do Rio Grande do Sul (RS), tem-se observado uma grande substituição anual de genótipos (Tabela 1). Por sua vez, quando se compara a média dos genótipos comuns em relação à média geral, observa-se um incremento no rendimento de grãos dos genótipos que permanecem no ensaio em relação aos retirados (Tabela 2). Isto significa que continuam nos ensaios linhagens com produtividade superior, pois foram descartadas as linhagens mal adaptadas e aquelas de que se requereu o registro. Durante os três biênios considerados nesse estudo, foram registradas para cultivo, no RS, as cultivares Pérola e Diamante Negro, ambas desenvolvidas pelo Centro Nacional de Pesquisa em Arroz e Feijão (CNPAF), Goiânia/ Goiás. Notase também uma redução na média de altura de inserção de primeiro e de último legume nos genótipos que permanecem nos ensaios, quando comparados aos eliminados. A diminuição na altura de inserção de primeiro legume poderá não ser favorável para cultivares que serão colhidas mecanicamente.Com relação ao ciclo e à massa 
Tabela 2 - Anos agrícolas, na seqüência de dois anos, número de genótipos (NG), média geral (MG) e média dos genótipos comuns (MC) para as características ciclo, rendimento de grãos, cor do tegumento dos grãos, altura de inserção do primeiro e do último legume, e massa de 100 grãos. Santa Maria-RS, UFSM, 2002.

\begin{tabular}{|c|c|c|c|c|c|c|}
\hline \multicolumn{7}{|c|}{ ANO AGRÍCOLA } \\
\hline & 98/99 & $99 / 00$ & $99 / 00$ & $00 / 01$ & $00 / 01$ & $01 / 02$ \\
\hline NG & 20 & 20 & 20 & 24 & 24 & 18 \\
\hline \multicolumn{7}{|c|}{ Ciclo (dias) } \\
\hline MG & 90,9 & 80,5 & 80,5 & 78,2 & 78,2 & 79,5 \\
\hline $\mathrm{MC}$ & 91,1 & 80,2 & 80,2 & 76,8 & 78,1 & 79,5 \\
\hline \multicolumn{7}{|c|}{ Rendimento de grãos $\left(\mathrm{kg} \mathrm{ha}^{-1}\right)$} \\
\hline MG & 2.527 & 2.693 & 2.693 & 1.525 & 1.525 & 1.196 \\
\hline $\mathrm{MC}$ & 2.760 & 2.575 & 2.802 & 1.782 & 1.539 & 1.196 \\
\hline \multicolumn{7}{|c|}{ Cor do tegumento dos grãos (L) } \\
\hline MG & 25,26 & 25,67 & 25,67 & 22,45 & 22,45 & 21,40 \\
\hline $\mathrm{MC}$ & 28,09 & 28,47 & 19,92 & 22,91 & 22,42 & 21,40 \\
\hline \multicolumn{7}{|c|}{ Altura de inserção do primeiro legume $(\mathrm{cm})$} \\
\hline MG & 12,75 & 8,99 & 8,99 & 14,71 & 14,71 & 25,49 \\
\hline $\mathrm{MC}$ & 11,95 & 8,82 & 9,04 & 14,59 & 13,88 & 25,49 \\
\hline \multicolumn{7}{|c|}{ Altura de inserção do último legume $(\mathrm{cm})$} \\
\hline MG & 51,50 & 37,22 & 37,22 & 33,27 & 33,27 & 55,83 \\
\hline $\mathrm{MC}$ & 50,93 & 35,97 & 35,72 & 36,32 & 31,52 & 55,83 \\
\hline \multicolumn{7}{|c|}{ Massa de 100 grãos (g) } \\
\hline MG & 23,81 & 23,89 & 23,89 & 20,66 & 20,66 & 18,93 \\
\hline $\mathrm{MC}$ & 25,05 & 23,47 & 24,79 & 21,36 & 20,55 & 18,93 \\
\hline
\end{tabular}

de 100 grãos, não se observaram mudanças expressivas nos quatro anos de avaliação. Se considerarmos os dados médios de 84 dias para ciclo e 20,6g para massa de 100 grãos, obtidos na mesma região (MANARA et al., 1993), pode-se concluir que estas duas variáveis mantêm-se estáveis, sugerindo que estes caracteres não estão sendo priorizados nos programas de melhoramento.

A estimativa para o ganho genético e sua evolução para as características avaliadas encontram-se na tabela 3. Observa-se ganho expressivo de $351 \mathrm{~kg} \mathrm{ha}^{-1}$ no rendimento de grãos dos genótipos considerados, no biênio 98/00, devido à inclusão das cultivares adaptadas: Macotaço, TPS Nobre, Carioca e Pérola. Isto demonstra que se pode elevar consideravelmente o potencial de produtividade do feijoeiro, quando se dispõe de cultivares adaptadas às condições edafoclimáticas da região (ELIAS et al., 1999). Por outro lado, valor negativo de ganho $\left(-148 \mathrm{~kg} \mathrm{ha}^{-1}\right)$ foi verificado no biênio 99/01. Esse valor representa uma perda genética, que pode ser atribuída a retirada das cultivares - Macotaço, Carioca e Pérola - e à inclusão de linhagens desenvolvidas por programas de melhoramento de outros estados, sem adaptação local, devido à reestruturação pela qual passaram os ensaios para registro de novas cultivares (CEPEF, 2000). Já no biênio $00 / 02$, um incremento de $14 \mathrm{~kg} \mathrm{ha}^{-1}$ foi observado. Provavelmente, esse menor ganho tenha sido função da manutenção de 18 genótipos comuns nesse período, pois se espera que o melhoramento possa contribuir com genótipos mais produtivos, quando promove alterações na composição dos experimentos (ANTUNES et al., 2000). O ganho genético médio anual para rendimento de grãos foi de $0,88 \%$, o que corresponde a $18,07 \mathrm{~kg} \mathrm{ha}^{-1}$ ano $^{-1}$. Esse valor é inferior ao encontrado em outros estados: 1,90\% em Minas Gerais (ABREU et al., 1994), 1,99\% no Paraná (FONSECA JÚNIOR et al., 1996a) e 1,21\% em Santa Catarina (ELIAS et al., 1999). No entanto, é muito similar ao ganho genético estimado por ANTUNES et al. (2000) nos ensaios conduzidos em rede no estado. Esses autores obtiveram estimativa de 0,74\%, o que corresponde a um ganho médio anual de $13,47 \mathrm{~kg} \mathrm{ha}^{-1}$ ano $^{-1}$.

Com relação à cor do tegumento dos grãos, nota-se, no biênio 99/01, que houve um ganho negativo de 6,21, causado pela retirada dos genótipos do grupo carioca, para satisfazer à nova estrutura dos ensaios de EVCU, que passaram a ser separados por grupo comercial (CEPEF, 2000). Entretanto, pode-se observar que praticamente inexistem genótipos com valores de $\mathrm{L}$ inadequados para feijões do grupo preto (CARNEIRO et al., 2000). Para esse grupo comercial, é importante dispor-se de genótipos com valores de $\mathrm{L}$ de 20 a 22, pois valores de L elevados (maior claridade) implicará na percentagem superior de grãos arroxeados, o que deprecia o valor comercial do feijão.

A estatura de planta do feijoeiro, na região da Depressão Central do RS, está diminuindo. Isto pode ser constatado pelo ganho médio anual negativo de 0,43 e de 1,87 para altura de inserção de primeiro e último legume, respectivamente.

O ciclo e a massa de 100 grãos têm apresentado ganho médio anual de pequena magnitude e positivo de 0,50 e 0,58 , respectivamente. Esse fato sugere que, para essas duas variáveis, os ganhos obtidos estejam sendo estáveis.

Diante desses fatos, pode-se inferir que ganhos em rendimento de grãos deverão ser de pequena magnitude. Sugere-se também que ganhos na altura de inserção de primeiro legume sejam priorizados a fim de possibilitar não somente a colheita mecanizada, mas também para prevenir a deterioração dos legumes que tocam no solo, em condições de excesso de umidade do solo (situação comum na região próximo à colheita). Finalmente, a qualidade tecnológica deverá receber mais atenção pelos 
Tabela 3 - Ganho genético anual e médio de três biênios e respectivo número de genótipos comuns para as diferentes variáveis observadas. Santa Maria-RS, UFSM, 2002.

\begin{tabular}{lrrr}
\hline & & Biênios & Média \\
\cline { 2 - 4 } Parâmetros & $98 / 00$ & $99 / 01$ & $00 / 02$ \\
\hline Genótipos comuns & 9 & 6 & 18 \\
Ciclo (dias) & 0,5 & 1,1 & $-0,1$ \\
Rendimento de grãos (kg ha $\left.{ }^{-1}\right)$ & 351 & -148 & 14 \\
Cor do tegumento dos grãos (L) & 0,03 & $-6,21$ & $-0,03$ \\
Altura de inserção do primeiro legume (cm) & $-0,63$ & $-0,83$ & $-2,07$ \\
Altura de inserção do último legume (cm) & 0,68 & 0,17 & $-1,75$ \\
Massa de 100 grãos (g) & 1,66 & $-4,55$ & $-0,11$ \\
\hline
\end{tabular}

melhoristas e investimentos pelos órgãos de fomento. Atualmente, há uma grande demanda por qualidade de alimentos e os produtos diferenciados, certamente, poderão dispor de maior representação do mercado.

\section{CONCLUSÕES}

O progresso anual obtido para rendimento de grãos na região da depressão central do Rio Grande do Sul, durante o período de 1998 a 2002, é comparável ao que se tem obtido em outros programas de melhoramento conduzidos no país, o que indica eficiência destes programas. O melhoramento genético do feijoeiro deverá investir também em aumento da inserção de primeiro legume e em qualidade tecnológica.

\section{REFERÊNCIAS BIBLIOGRÁFICAS}

ABREU, A.F.B. et al. Progresso do melhoramento genético do feijoeiro nas décadas de setenta e oitenta nas regiões sul e Alto Paranaíba em Minas Gerais. Pesquisa Agropecuária Brasileira, Brasília, v.29, n.1, p.105-112, 1994

AGROANALYSIS. Preços recebidos. Rio de Janeiro : FGV, 1998. V.18, n.4.

ANTUNES, I.F. et al. Progresso no melhoramento genético do feijão no Rio Grande do Sul, no período 1987/ 88 - 1998/99. In: REUNIÃO TÉCNICA ANUAL DO FEIJÃO E IV REUNIÃO SUL-BRASILEIRA DO FEIJÃO, 33, 2000, Santa Maria. Anais... Santa Maria : UFSM, 2000. CD-ROM.

CEPEF. Feijão: recomendações técnicas para cultivo de feijão no Rio Grande do Sul. Santa Maria : PALLOTTI, 2000. 80 p

CARNEIRO, G.E.S.; SOARES, D.M., COSTA, J.G.C. Resultados do ensaio Sul-Brasileiro de avaliação de linhagens de feijão nos anos 1997/98 e 1998/99. Santo
Antônio de Goiás : Embrapa Arroz e Feijão, 2000. 77p. (Embrapa Arroz e Feijão. Documentos, 102).

ELIAS, H.T.; HEMP, S.; FLESCH, R.D. Ganho genético na produtividade das cultivares de feijão recomendadas para Santa Catarina - 1979/1999. In: REUNIÃO NACIONAL DE PESQUISA DE FEIJÃO, 6., 1999, Goiânia. Anais... Goiânia: EMBRAPA, 1999. p.373-375

FONSECA JÚNIOR, N.S. et al. Estimativas do ganho genético para o feijão do grupo preto no Paraná. In: REUNIÃO NACIONAL DE PESQUISA DE EIJÃO, 5., 1996, Goiânia. Anais... Goiânia : EMBRAPA, 1996a. p.295-297.

FONSECA JÚNIOR, N.S. et al. Estimativas do ganho genético para o feijão do grupo cores no Paraná. In: REUNIÃO NACIONAL DE PESQUISA DE EIJÃO, 5., 1996, Goiânia. Anais... Goiânia : EMBRAPA, 1996b. p.298-300.

MANARA, W. et al. Avaliação de genótipos de feijoeiro em Santa Maria, RS. Ciência Rural, Santa Maria, v.23, n.2, p.161-164, 1993

POMPEU, A.S. Feijão. In: FURLANI, A.M.C.; VIÉGAS, G.P. O melhoramento de plantas no Instituto Agronômico. São Paulo : Imprensa Oficial do Estado de São Paulo, 1993. p.111-156.

RAMALHO, M.A.P. Melhoramento genético de plantas no Brasil: situação atual e perspectivas. In: CONGRESSO BRASILEIRO DE MELHORAMENTO DE PLANTAS, 1., 2001, Goiânia. Anais... Goiânia : EMBRAPA, 2001. CDROM.

ROLAS. Recomendação de adubação e calagem para os estados do Rio Grande do Sul e Santa Catarina. 3.ed. Passo Fundo : SBCS, 1995. 223p.

VENCOVSKY, R. et al. Progresso genético em vinte anos de melhoramento de milho no Brasil. Piracicaba : (s.n.), 1986. 22p.

VENCOVSKY, R., RAMALHO, M.A.P. Contribuição do melhoramento genético de plantas no Brasil. In: PATERNIANI, E. (ed.). Agricultura brasileira e pesquisa agropecuária. Brasília: EMBRAPA, 2000. p.57-89. 